\title{
Managed care, office systems and medical liability risk
}

\author{
Dean G. Smith*1, Xiao Xu², Kathryn R. McCool ${ }^{3}$ \\ ${ }^{1}$ School of Public Health, Louisiana State University Health Science Center, New Orleans, LA, USA \\ ${ }^{2}$ Department of Obstetrics, Gynecology, and Reproductive Sciences and Institute for Social and Policy Studies, School of \\ Medicine, Yale University, New Haven, CT, USA \\ ${ }^{3}$ School of Nursing, Louisiana State University Health Science Center, New Orleans, LA, USA
}

Received: June 30, 2015

DOI: $10.5430 /$ ijh.v1n1p13

\author{
Accepted: July 27, 2015 \\ Online Published: July 30, 2015 \\ URL: http://dx.doi.org/10.5430/ijh.v1n1p13
}

\begin{abstract}
Objective: Medical liability continues to be a concern among physicians and policy makers. This study examines the interaction among managed care, the systems that physicians put into place in their offices to address managed care demands and their resultant medical liability risks.

Methods: A survey instrument based on a conceptual model of risk was mailed to 882 physicians identified by a medical liability insurance company. Multivariate methods were used to compare rates of claims of medical liability with managed care involvement, office systems and risk management techniques.

Results: A total of 393 physicians completed a mail survey, with an overall response rate of $45 \%$. Of respondents, 137 had no claims in the prior two years, 109 had only one claim, and 147 had two or more claims. Having a higher percentage of managed care patients was associated with higher risk $(p<.01)$. Changing office systems $(p<.05)$ and spending more time on risk management $(p<.01)$ were associated with lower risk. Specific risk management techniques were not associated with differences in risk.

Conclusions: Having more managed care patients is associated with a higher risk of malpractice claims. However, more investment in office systems and risk management can help offset such risks. Unfortunately, this study was unable to provide direction on the most effective office systems or risk management techniques to employ.
\end{abstract}

Key Words: Risk management, Managed care, Office systems, Medical liability, Malpractice

\section{INTRODUCTION}

Managed care has become the dominant form of health insurance in employment-based insurance markets, ${ }^{[1]}$ and important in Medicaid and Medicare as well. ${ }^{[2]}$ This diffusion of managed care has influenced the U.S. health care system in numerous ways, including, possibly, the frequency of medical liability claims. Typical managed care arrangements include having primary care physicians responsible for referral to specialists, utilization review, and submission and review of claims, administrative and medical records data. ${ }^{[3,4]}$ Physicians report that participation in managed care has had significant effects on clinical decision-making and other aspects of medical practice: physician-patient relationships, administrative burdens and referral limitations. ${ }^{[5]}$

There has long been wide-spread concern that changes in the physician-patient relationship and/or other responses to managed care may result in higher medical liability risks. ${ }^{[6]}$ The cost containment motivation among managed care plans also restricts practice of "defensive medicine" by physicians,

\footnotetext{
*Correspondence: Dean G. Smith; Email: dgsmith@1suhsc.edu; Address: School of Public Health, Louisiana State University Health Science Center, 2020 Gravier Street, New Orleans, LA 70112, USA.
} 
that is, actions such as increasing referral rates, increasing follow-up, increasing testing and prescription of marginally necessary drugs to control liability risks. ${ }^{[7]}$ Moreover, issues raised in medical liability suits often involve treatments and procedures that require managed care authorization. ${ }^{[8]}$

The pressures of managed care may be hitting a cross-road with the pressures of maintaining good physician-patient communication and tactics designed to limit medical liability risks. With the current calls for changes in managed care arrangements and continuing concerns about medical liability insurance rates, we envision the potential for another liability insurance crisis. Tort reforms are again a potential solution. ${ }^{[9]}$ However, the medical marketplace has changed substantially in recent years. Most notably, the passage of the Affordable Care Act and the introduction of accountable care organizations suggest that both more persons will be covered by health insurance and the managed care form of health insurance is experiencing growth. The underlying process of handling managed care patients and handling the administrative aspects of managed care have changed in ways that are not well understood.

While it may be that there is a direct relationship between managed care and liability risk, it is possible that the intervening component of office systems plays an important role in this relationship that merits careful investigation. Developing policies to address liability issues may be enlightened by a good understanding of the complex managed care-office systems-risk relationship. Unfortunately, there has been a dearth of research connecting managed care and liability risks in a manner that addresses how managed care changes practices and what the relationships are among managed care, office systems and risk. In this study, we seek to fill this gap in the literature and examine the interaction among managed care, the systems that physicians put into place in their offices in response to managed care, and the medical liability risks faced by physicians.

\section{METHODS}

\subsection{Conceptual model}

The fundamental research question in this study is: what are the relationships among managed care, office systems and medical liability risks? Our hypothesis is that the managed care - risk relationship is indirect, and we offer a conceptual model of managed care, office systems and risk as represented by Figure 1. Managed care requires documentation and administrative activity in the areas of access, satisfaction, utilization and costs. Managed care requirements may be met by systems for patient flow and office operations. The high costs of meeting the demands of insurance have been well-documented. ${ }^{[10,11]}$ The changes that occur in of- fice systems in response to managed care may affect liability risks - positively or negatively. Managed care's emphasis on ease of access, member satisfaction and documentation may serve to reduce liability claims. Managed care's emphasis on utilization management, efficiency and changing patient expectations, however, may be associated with a greater number of claims.

\begin{tabular}{|c|c|c|}
\hline $\begin{array}{r}\text { Response to } \\
\text { Demands }\end{array}$ & $\begin{array}{r}\text { Selected } \\
\text { Consequences }\end{array}$ & \\
\hline Managed Care Demands & Physician Office Systems & Risks \\
\hline Member satisfaction & Satisfaction surveys & Changing patient expectations \\
\hline Utilization management & Referral authorization & Treatment denials or delays \\
\hline Encounter documentation & Chart review & Open records \\
\hline Efficiency & Visit management & Changing time per visit \\
\hline Price discounts & Accounting & Changing communication \\
\hline
\end{tabular}

Figure 1. A conceptual model of managed care, office systems and medical liability risk

\subsection{Survey}

To test the conceptual model, we conducted a mail survey on physicians' involvement with managed care and the resulting changes in their office systems. A complete list of physicians who had professional liability insurance coverage solely through a single medical liability insurance carrier was used as the sampling frame. A stratified random sample was drawn from this list. Stratification was based on the number of malpractice claims that physicians had in the two-year period prior to the survey, regardless of their resolution (e.g., dropped, settled, won or lost). Three strata were generated: no claim, one claim, and two or more claims. Three hundred physicians were drawn randomly, with replacement, from each stratum. The final sample contained 882 physicians (there were 18 duplicates of names due to the replacement process). Of them, 289 had no claims, 298 had only one claim, and 295 had two or more claims. By design, this survey over sampled physicians with claims, as an average of just over seven percent of physicians have a claim in a given year. ${ }^{[12]}$

To ensure the face and content validity of an internallydeveloped survey instrument, we performed pilot testing among a small group of physicians. Additional comments were elicited from local medical association staff. The survey instrument was subsequently revised based on comments and suggestions received during this process. The final questionnaire contained 120 items ascertaining a physician's demographic background, medical training experience, practice characteristics, involvement with managed care, and office systems and risk management efforts.

A survey packet containing a cover letter, the questionnaire and a postage-paid return envelope was mailed to our sample of 882 physicians. Two weeks after this initial mailing, a postcard reminder was sent to each physician to solicit 
response. This study was approved by the University Institutional Review Board. As explained in a cover letter, submission of a survey response constituted consent to participate in the study, and confidentiality of respondents was assured.

\subsubsection{Outcome variable}

The primary outcome variable in this study is the number of malpractice claims that a physician had during the two-year period preceding the survey, i.e., no claim, one claim, and two or more claims. They serve as a proxy for the physician's level of risk for malpractice claims (low risk, medium risk, and high risk, respectively).

\subsubsection{Explanatory variables}

The primary explanatory variables in this study are managed care involvement and changes in office systems in order to address managed care demand. Managed care involvement is measured by physician self-reported percentage of patients insured by managed care (including health maintenance organizations [HMOs] and preferred provider organizations [PPOs]). Regarding changes in office systems, the survey asked respondents: "Have you changed your practice in response to HMO or PPO arrangements in the past two years?" The physician could select one or more of the following: hired additional professional staff (e.g., registered nurse); hired additional office staff (e.g., billing staff); changed referral patterns; changed prescribing patterns; purchased new computer systems/software; or made other changes. We use the sum of changes (ranging from zero to six) to measure the extent of change in medical practice systems in response to managed care arrangement.

Other important explanatory variables include respondents' overall efforts in risk management, as measured by selfreported percentage of time spent on risk management, and several composite measures reflecting specific risk management practices. In particular, respondents were asked about the eight documentation items suggested in risk management textbook, ${ }^{[13]}$ including discussions on patient's presenting complaint, discussion with patient regarding test results, referrals, proposed treatment, patient's understanding of proposed treatment, unplanned events (complications of treatment), discussions with a referring physician, and communications with a managed care plan. The number of these items that each respondent documented in medical records is used to measure his/her level of documentation effort.

Similarly, respondents reported: (1) their sources of risk management information (from a list of six possible sources): insurance company, American Medical/Osteopathic Association, specialty society, consultants, State Medical Soci-

Published by Sciedu Press
ety/State Osteopathic Association, or other specified source; (2) specific practices taken to handle patient consent process (from a list of four possible practices): existence of a policy, system or procedure for documenting "informed consent" discussions with the patient, notifying appropriate personnel of a misdiagnosis, identifying adverse events, and evaluating an incident that results in serious injury or death; and (3) practices adopted to protect patient information (from a list of nine possible practices): existence of a policy or procedure for the release of medical records, education of office staff about the importance of patient confidentiality, when staff may take a telephone call from a patient and when the physician must take it, telephone follow-up, location of fax machine handling patient information (out of sight of patients and visitors), use of e-mail communication with patients, e-mail follow-up, and special informed consent policies for e-mail. For each of the three categories, we use the actual number of sources (or practices) used by the physician to measure his/her extent of risk management activities.

To determine the interaction effects of risk management efforts and managed care impact, our model also include two interaction terms: one for the interaction of overall risk management efforts (i.e., time spent on risk management activities) and managed care involvement, and the other for the interaction of overall risk management efforts (i.e., time spent on risk management activities) and changes in office systems to address managed care.

The model also adjusts for other factors, including physicians' gender, year of graduation from medical school, location of medical school, medical specialty, DO and MD degree, and volume of patient activity as measured by the percentage of time engaged in direct patient care.

\subsection{Statistical analysis}

We calculate descriptive statistics to determine respondents' demographics, characteristics of clinical practice, managed care involvement, and risk management activities. Bivariate analyses are conducted to examine differences in these characteristics by physicians' medical liability outcome. For this purpose, we use chi-square tests for categorical variables and analysis of variance (ANOVA) for continuous variables.

To control for other factors that might affect medical liability outcome, we also perform multivariable regression analyses using binary probit models. The primary outcome variable is medical liability risk, measured by a categorical variable with 0 representing no malpractice claim, 1 representing only one claim and 2 signifying two or more claims. Analyses are conducted by dichotomizing medical liability risk into two binary variables: having one or more malpractice claims 
(versus no claim), and having two or more claims (versus no claim or just one claim). Binary probit models are used for this purpose. All data analyses are conducted using STATA statistical software version 8.2 (StataCorp, College Station, TX). A $p$-value less than .05 is considered to be statistically significant.

\section{RESULTS}

A total of 393 physicians completed the survey, with an overall response rate of $45 \%$. Of them, 137 had no claim, 109 had only one claim, and 147 had two or more claims. Compared to other physicians who had no claim or two/more claims, a slightly lower proportion of physicians with one claim responded to the survey. Potential reasons for this difference in response rate are not assessable as, other than number of malpractice claims, all data for this study are ascertained from survey responses. Hence no information on non-respondents' characteristics is available.

The characteristics of survey respondents are presented in Table 1. In general, the characteristics of survey respondents are similar to the state physician population except that our sample had higher proportions of physicians in solo practice and physicians in primary care. ${ }^{[14]}$ Many characteristics, including practice type, board certification and time spent on direct patient care, are comparable across claims categories. Compared with respondents who graduated from out-of-state medical schools, those graduating from a medical school within the state are less likely to have two or more malpractice claims made against them. Without adjustment for other factors, having a DO degree as opposed to an MD degree is associated with a higher likelihood of having more than one claim.

Respondents' involvement with managed care and information about their office system changes and risk management practices are summarized in Table 2. On average, physicians reported that one third of their patients were covered through an HMO or a PPO. In response to managed care demands, respondents had hired additional office staff (43\%), purchased new computer systems (39\%), and altered referral (48\%) or prescribing patterns $(51 \%)$. More than $80 \%$ of them reported at least one of these changes in office systems, and an average physician cited two of such changes.

With respect to risk management practices, respondents reported spending $16 \%$ of their time on such activities (e.g., documentation, quality assurance or utilization review due to liability concerns), rising from $9 \%$ five years ago. Physicians reported an average of three sources from which they received advice or suggestions for risk management practices. Insurers are the most frequently cited source of information, with state medical/osteopathic societies also a source for more than half of physicians.

Documentation, informed consent and patient information protection are some closely related issues pertaining to risk management. Of the eight items of documentation, an average respondent documented six of them. Physicians in our sample had an average of two established policies regarding patient informed consent. The vast majority of respondents had some policies or procedures to address communication issues, including information contained in written, telephonic and e-mail communications. On average, physicians implemented five types of procedures to protect patient information.

Results from multivariable regression analysis are shown in Table 3. Binary probit models are estimated for one/more claims versus no claim, and two/more claims versus no claim or one claim, respectively. Managed care involvement, office systems, risk management and the interactions of managed care involvement and office systems with risk management time significantly affect physicians' liability risk. For each 10 percentage point increase in managed care patients (e.g. from $30 \%$ of patients to $40 \%$ of patients), physicians are $2.0 \%$ more likely $(p<.01)$ to have one or more claims, as opposed to no claim; or $3.5 \%$ more likely $(p=.06)$ to have two or more claims, as opposed to no claim or one claim (evaluated at sample means). These increased risks can be off-set by similar magnitudes though investing in one additional office system change to address managed care demand (2.0\% $[p=.03]$ and $4.4 \%[p=.12]$, respectively) (evaluated at sample means). In both cases the results are statistically significantly different from zero for the case of one claim and not significant for the case of two or more claims. Again, the unadjusted likelihood of having any claims in a given year is $7.4 \%$, and among those with any claims, $67 \%$ have only one claim and $21 \%$ have two claims. ${ }^{[12]}$ Therefore, the first set of results is highly relevant.

Spending more time on risk management is associated with a statistically significant lower likelihood of having one or more claims $(p<.01)$, though it would take a substantial portion of time to yield a meaningful risk reduction. A five percentage point increase in time spent on risk management is required for each one percentage point reduction in risk of having a claim. The interactions of risk management time with managed care involvement and office systems both have significant effects on medical liability outcomes. Having more managed care patients enhances the effectiveness of risk management - partially offsetting the increased risk associated with managed care patients. On the other hand, investing more efforts in risk management and office systems 
is associated with diminishing marginal returns, such that tion terms are associated with changes that are an order of the risk management time lessens the risk reduction benefits magnitude smaller than the direct effects. Surprisingly, more associated with office systems. However, each of the interac- documentation activities are associated with more claims.

Table 1. Characteristics of physicians in the sample

\begin{tabular}{llllll}
\hline Characteristics & Overall & No Claims & One Claim & $\begin{array}{l}\text { Two/More } \\
\text { Claims }\end{array}$ & $\begin{array}{l}\boldsymbol{p} \text {-value of } \\
\text { Difference }\end{array}$ \\
\hline Sample size (n) & 393 & 137 & 109 & 147 & \\
Female (vs. Male) & $12 \%$ & $20 \%$ & $12 \%$ & $6 \%$ & .002 \\
Graduation from medical school 1960s or before & $47 \%$ & $42 \%$ & $38 \%$ & $58 \%$ & .002 \\
Graduation from medical school from other state & $34 \%$ & $26 \%$ & $28 \%$ & $42 \%$ & .007 \\
Graduation from medical school from other country & $17 \%$ & $12 \%$ & $19 \%$ & $18 \%$ & .298 \\
Medical degree DO (vs. MD) & $18 \%$ & $10 \%$ & $11 \%$ & $30 \%$ & .000 \\
Surgical specialty & $8 \%$ & $7 \%$ & $3 \%$ & $13 \%$ & .000 \\
Obstetrics/Gynecology & $5 \%$ & $2 \%$ & $3 \%$ & $10 \%$ & .000 \\
Other Specialty & $14 \%$ & $15 \%$ & $17 \%$ & $12 \%$ & .000 \\
Not Board certified & $13 \%$ & $9 \%$ & $14 \%$ & $16 \%$ & .160 \\
Solo practice & $51 \%$ & $50 \%$ & $59 \%$ & $47 \%$ & .161 \\
Time engaging in direct patient care now & $81 \%$ & $83 \%$ & $81 \%$ & $84 \%$ & .561 \\
Time engaging in direct patient care five years ago & $83 \%$ & $89 \%$ & $84 \%$ & $89 \%$ & .678 \\
\hline
\end{tabular}

Table 2. Managed care involvement, office systems, and risk management practices among physicians

\begin{tabular}{|c|c|c|c|c|c|}
\hline Characteristics & Overall & No Claims & One Claim & $\begin{array}{l}\text { Two/More } \\
\text { Claims }\end{array}$ & $\begin{array}{l}p \text {-value of } \\
\text { Difference }\end{array}$ \\
\hline Percentage of patients with managed care coverage ${ }^{*}$ & $34 \%$ & $34 \%$ & $40 \%$ & $35 \%$ & .095 \\
\hline Practice changes in response to managed care arrangement ${ }^{* *}$ & 2.1 & 1.9 & 2.2 & 2.0 & .212 \\
\hline Time spent on risk management now & $16 \%$ & $19 \%$ & $14 \%$ & $18 \%$ & .112 \\
\hline Time spent on risk management five years ago & $9 \%$ & $11 \%$ & $7 \%$ & $10 \%$ & .045 \\
\hline Number of risk management information sources ${ }^{* * *}$ & 2.6 & 2.7 & 3.2 & 2.6 & .044 \\
\hline Number of items documented in medical records ${ }^{* * * *}$ & 6.4 & 6.1 & 6.8 & 6.4 & .010 \\
\hline Number of informed consent practices ${ }^{* * * * *}$ & 2.3 & 2.4 & 2.2 & 2.2 & .311 \\
\hline Number of patient information protection practices ${ }^{* * * * * *}$ & 4.9 & 4.8 & 5.2 & 4.7 & .073 \\
\hline
\end{tabular}

Note. ${ }^{*}$ Managed care plans include both health maintenance organizations (HMOs) and preferred provider organizations (PPOs). ${ }^{* *}$ Respondents could choose from a list of six changes: hired additional profession staff (e.g., Registered Nurse), hired additional office staff (e.g., billing staff), purchased new computer systems/software, changed referral patterns, changed prescribing patterns, other specified change. ${ }^{* * *}$ Respondents could choose from a list of five sources including insurance company, American Medical/Osteopathic Association, specialty society, consultants, Michigan State Medical Society/Michigan Osteopathic Association, or specify other sources. ${ }^{* * * * *}$ Respondents could choose from a list of eight documentation items including discussions with patient about presenting complaint, test results, proposed treatment, referrals, and unplanned events, patient's understanding of proposed treatment, discussions with a referring physician, and communications with a managed care plan. ${ }^{* * * * *}$ Respondents could choose from a list of four informed consent practices including existence of a policy requiring documentation of an "informed consent" discussion with the patient, a system/procedure for notifying appropriate personnel of a misdiagnosis, a process for identifying adverse events, and a procedure for evaluating an incident that results in serious injury or death. ${ }^{* * * * * * *}$ Respondents could choose from a list of nine patient information protection practices including existence of a written policy for releasing medical records, a procedure for educating office staff regarding the importance of patient confidentiality, a policy for when staff may take a telephone call from a patient and when the physician must take it, a policy or written guidelines for any staff involved in providing telephone advice, a procedure to address telephone follow-up, location of fax machine handling patient information (out of sight of patients and visitors), e-mail communication with patients, existence of special informed consent policies for e-mail, and a procedure to address e-mail follow-up.

Findings about the effects of control variables on medical liability risk are generally consistent in both regressions. The ones shown to be statistically significant at the 0.05 level are gender, location of medical school, medical specialty and medical degree. Specifically, female as opposed to male physicians are less likely to have had more claims made against them in the past two years. International medical graduates as opposed to Michigan graduates are more likely to have claims, and physicians with a specialty other than surgery and obstetrics/gynecology are less likely than family medicine/general practice physicians to have claims. Finally, DO's are more likely than MD's to have malpractice claims. 
Table 3. Results from multivariable regression analysis (binary probit model)

\begin{tabular}{|c|c|c|c|c|}
\hline \multirow[t]{2}{*}{ Variables } & \multicolumn{2}{|c|}{$\begin{array}{l}\text { One/More Claim versus } \\
\text { No Claim }\end{array}$} & \multicolumn{2}{|c|}{$\begin{array}{l}\text { Two/More Claims versus } \\
\text { No/One Claim }\end{array}$} \\
\hline & Coefficient & Std. Err. & Coefficient & Std. Err. \\
\hline Percentage of managed care patients & $0.0181^{* *}$ & 0.0050 & 0.0096 & 0.0051 \\
\hline Changes in office systems & $-0.1800^{*}$ & 0.0810 & -0.1211 & 0.0778 \\
\hline Time spent on risk management & $-0.0178^{* *}$ & 0.0062 & 0.0104 & 0.0063 \\
\hline Time spent on risk management $\times$ Managed care patients & $-0.0007^{* *}$ & 0.0002 & $-0.0007^{* *}$ & 0.0002 \\
\hline Time spent on risk management $\times$ Changes in office systems & $0.0130^{* *}$ & 0.0033 & $0.0087^{* *}$ & 0.0032 \\
\hline Risk management information sources & 0.0083 & 0.0719 & 0.0104 & 0.0652 \\
\hline Documentation & $0.1942^{* *}$ & 0.0482 & -0.0108 & 0.0472 \\
\hline Patient informed consent & -0.0682 & 0.0594 & -0.0106 & 0.0606 \\
\hline Patient information protection & -0.0017 & 0.0525 & -0.0973 & 0.0522 \\
\hline Female & $-0.9772^{* *}$ & 0.2565 & -0.3572 & 0.2598 \\
\hline Year of graduation from medical school $<1970$ & 0.0406 & 0.1639 & $0.6382^{* *}$ & 0.1683 \\
\hline U.S. states other than Michigan (vs. Michigan) & 0.0618 & 0.1818 & $0.4734^{*}$ & 0.1807 \\
\hline Other country (vs. Michigan) & $1.1829^{* *}$ & 0.2095 & 0.3202 & 0.2151 \\
\hline Surgical specialty (vs. Family/General practice) & -0.4376 & 0.2382 & 0.3440 & 0.2200 \\
\hline Obstetrics/gynecology specialty (vs. Family/General practice) & -0.1471 & 0.4315 & 0.3709 & 0.3546 \\
\hline Other Specialty (vs. Family/General practice) & $-0.6094^{* *}$ & 0.1790 & $-0.5098^{* *}$ & 0.1847 \\
\hline Not board certified & 0.0490 & 0.2499 & 0.1753 & 0.2650 \\
\hline Solo practice & 0.3067 & 0.1705 & -0.1844 & 0.1819 \\
\hline DO degree (vs. MD degree) & $0.5752^{* *}$ & 0.2243 & $0.8561^{* *}$ & 0.1941 \\
\hline Percentage of time spent on direct patient care & 0.0052 & 0.0032 & 0.0039 & 0.0035 \\
\hline Constant & 0.2161 & 0.4310 & -0.8410 & 0.4487 \\
\hline Pseudo $\mathrm{R}^{2}$ & \multicolumn{2}{|c|}{0.2067} & \multicolumn{2}{|c|}{0.1843} \\
\hline Sample size & \multicolumn{2}{|c|}{340} & \multicolumn{2}{|c|}{340} \\
\hline
\end{tabular}

Note. Statistical significance: ${ }^{*} p<.5,{ }^{* *} p<.01$

\section{Discussion}

As the market share of managed care keeps growing and the medical liability costs remain a concern, examining the interaction among managed care, the office systems in response to managed care arrangements and the physician's ensuing medical liability risk can provide important implications for addressing the potential advent of another liability crisis. ${ }^{[15]}$ Using survey data collected in one state, the present study investigates the subtle relationship among the three. The results suggest that managed care patient share, office systems and risk management efforts are all significant factors for medical liability risk. Physicians with a higher percentage of managed care patients in their practice are more likely to have malpractice claims filed against them; yet implementing changes in office systems in response to managed care can help offset such risks.

In general, our results provide evidence consistent with the concern that proliferation of managed care may expose physicians to higher risk of medical liability. Managed care plans frequently select or exclude physicians based on a num- ber of criteria, including compliance with administrative requests. ${ }^{[4,16]}$ While physicians try to balance administrative and patient care demands by modifying office systems, the administrative burden has undoubtedly limited the amount of time physicians may spend on patient care. The various arrangement of managed care, such as gatekeeping and authorization for specialty referrals, also jeopardize physicianpatient relationship. ${ }^{[16]}$ One study found that having more managed care patients in a physician's panel is associated with lower patient satisfaction with the provider. ${ }^{[17]}$ With the quantity and quality of physician-patient communication being reported as a possible predictor of medical liability claims, ${ }^{[18-20]}$ it is possible that physicians with higher managed care involvement are more vulnerable to malpractice claims.

Nonetheless, the results of this study should not be interpreted such that physicians should drop or cease taking care of patients from managed care plans. Though liability risk may be an important component of a medical practice, it is neither the only nor the most important component. More- 
over, as shown in this study, some of the office systems adopted in response to managed care demands can help lower the likelihood of having claims. The amount of protection produced by one additional office system change is equivalent to the incremental risk associated with $10 \%$ higher managed care patient share. Note that these office system changes are adopted to respond to managed care demands, rather than directly for the purpose of risk management. To the extent that physicians are considering office systems to handle managed care arrangements, the risk management functions are a side-effect that may weigh in marginal decisions. Encouragingly, our survey data show that a fair proportion of physicians are already using office systems to address the risk.

The observed beneficial impact of risk management efforts on reducing liability risk provides additional opportunities for physicians. Investing more time in risk management activities can partially offset the increased risk associated with having more managed care patients. Therefore, by developing effective office systems and implementing appropriate risk management practices, physicians would be able to lower their risk level even when they cannot reduce contracts with managed care. Unfortunately, this study was unable to provide direction on the most effective office systems or risk management techniques. There are many guidelines and suggestions for office systems and techniques. No individual system or technique was associated with a statistically significant relationship with claims.

One result that gives pause in presentation and interpretation is the negative results related to documentation. It is difficult to see how increased documentation would be associated with increased liability. Most recommendations in the area of liability control include documentation. ${ }^{[9,21]}$ Possibly, the causal ordering is that physicians who have had liability claims made against them engage in more documentation. This alludes to one limitation of the present study: the outcome variable and office practices are measured over the same time period. Hence an altered causation for some of the variables is a possibility. Future research capable of disentangling these factors is recommended.

There are a host of other limitations of the study should be acknowledged. First, our outcome variable is a crude measure of medical liability risk. It does not reflect the true outcomes of the claims, which may end up being dropped or the physician may win the lawsuit. There is a long lag time between the incidents that may give rise to claims. ${ }^{[22]}$ Only claims filed in the past two years are measured here. Claims here are also measured as all claims, without reference to whether they were associated with managed care patients, fee-for-service patients, patient covered by Medicare, Medicaid or commercial insurance. Each group of patients may have different needs, and policies associated with treatment and these needs and policies can change frequently and over time. Hence the relationship measured in this study may not precisely characterize the impact of managed care and office systems on liability risk in today's marketplace.

Second, some factors that could possibly affect liability risk are not considered or not measured in depth. For instance, we do not consider all types of systems and styles employed in physician offices in response to managed care arrangement. Rather, respondents were asked to choose from a limited list of practices. In addition, other personal and professional characteristics of physicians that may be related to medical legal claims are not fully elucidated in this study. For example, the most popular physicians, based on various personal characteristics and professional expertise, may be less likely to accept managed care arrangements. Similarly, physicians that are unable to attract fee-for-service clients may be more likely to accept lower compensated managed care reimbursement. While these physician characteristics may be directly related to medical-legal risk, we did not systematically evaluate these issues. Finally, similar to other survey studies, our findings are based on physician self-reported data and their memories and perceptions of how they spend their time. Their actual practices regarding office systems and risk management may differ from what they report in the survey.

Third, there are many factors which continue to evolve that affect office systems that are unrelated to managed care and relate to all patients. To the extent that office practices have increased in size associated with more patients alone or formation of groups of physicians and their patients, there may be increases in office staffing. Health Insurance Portability and Accountability Act (HIPAA) provisions increased the documentation, consent and security of patient data, which is particularly important and potentially cumbersome for managed care patients whose contracts require much data sharing. American Recovery and Reinvestment Act (ARRA) provisions provide for meaningful use of electronic medical records that substantially contributed to investments in office systems. Many states have engaged in tort reform, and physicians have moved away from markets with unfavorable liability regulations. ${ }^{[23]}$ The associations between changes in practice sizes, HIPAA provisions, ARRA provisions, tort reform, and the relationships between office systems and medical liability risks are open questions that merit separate investigation. This study is also narrowly focused on practice in the United States and applications for other health systems is unclear. Readers in other health systems may benefit from 
a review of managed care terms. ${ }^{[24]}$

Overall, this study suggests that the relationship among managed care, office systems and medical liability risk is subtle. Though higher managed care caseloads increases physicians' likelihood of having claims, time and resources devoted to office systems, including risk management systems, in response to managed care contracting may help mitigate such risks. Further exploration of this conceptual model and the interaction among factors is recommended.

\section{ACKNOWLEDGEMENTS}

The authors acknowledge the financial support of the Blue Cross Blue Shield Foundation, the work of professor Peter D. Jacobson, the work of research assistant Tracy L. Finlayson, provision of data from APA Capital (Steven Trosty) and technical assistance from the Michigan Osteopathic Association (Dennis Paradis) and the Michigan State Medical Society (Mary Anne Ford). Of course, all matters of opinion expressed in this report and all errors and omissions are those of the authors.

\section{REFERENCES}

[1] Sanofi-Aventis. HMP-PPO Digest, 28th edition, 2014. Available from: https://managedcaredigest.com/pdf/HMO-PPO.pdf

[2] Paradise J. Key findings on Medicaid managed care: Highlights from the Medicaid managed care market tracker. Kaiser Family Foundation, December 2014. Available from: http://files.kff.org/attachment/key-findings-on-m edicaid-managed-care-highlights-from-the-medicai d-managed-care-market-tracker-report

[3] Anthony D. Changing the nature of physician referral relationships in the US: The impact of managed care. Social Science \& Medicine. 2003; 56(10): 2033-2044. http://dx.doi.org/10.1016/S0277 $-9536(02) 00198-3$

[4] Unruh L, Lugo NR, White SV, et al. Managed care and patient safety: Risks and opportunities. The Health Care Manager. 2005; 24(3): 245-56. PMid: 16131935. http://dx.doi.org/10.1097/00126 450-200507000-00009

[5] Shen J, Andersen R, Brook R, et al. The Effects of Payment Method on Clinical Decision-Making: Physician Responses to Clinical Scenarios. Medical Care. 2004; 42(3): 297-302. PMid: 15076830. http: //dx.doi.org/10.1097/01.mlr.0000114918.50088.1c

[6] Schwartz JC. A dose of reality for medical malpractice reform. NYU Law Review. 2013; 88(4): 1124-1307.

[7] Barkowski S. Does defensive medicine reduce health care spending? Munich Personal RePEc Archive Paper No. 64318, 2015. Available from: http://mpra.ub.uni-muenchen.de/64318/

[8] Plumeri PA. Managed care and risk management. Gastroenterology Clinics of North America. 1997; 26(4): 895-910. http://dx.doi . org/10.1016/S0889-8553(05) 70340-X

[9] Mello MM, Studdert DM, Kachalia A. The medical liability climate and prospects for reform. JAMA. 2014; 312(20): 2146-2155. PMid: 25358122. http://dx.doi.org/10.1001/jama.2014.10705

[10] Casalino LP, Nicholson S, Gans DN, et al. What does it cost physician practices to interact with health insurance plans? Health Affairs. 2009; 28(4): w533-w543. PMid: 19443477. http://dx.doi.org /10.1377/hlthaff.28.4.w533

[11] Sakowski JA, Kahn JG, Kronick RG, et al. Peering into the black box: billing and insurance activities in a medical group. Health Affairs. 2009; 28(4): w544-w554. PMid: 19443478. http://dx.doi.org $/ 10.1377 /$ hlthaff.28.4.w544

[12] Jena AB, Seabury S, Lakdawalla D, et al. Malpractice risk according to physician specialty. New England Journal of Medicine. 2011; 365(7): 629-636. PMid: 21848463. http://dx.doi.org/10.10 56/NEJMsa1012370
[13] Youngberg BJ. Risk Management Desk Reference, 2nd edition. Burlington, MA: Jones \& Bartlett; 1998.

[14] Michigan State Medical Society. The future supply and demand for physicians in Michigan. Lansing, MI: MSMS; 2005. Available from: http://www.msms.org/

[15] Rodwin MA, Silverman J. Why the medical malpractice crisis persists even when malpractice insurance premiums fall. Health Matrix: Journal of Law-Medicine. 2015; 25(1): 14-27.

[16] Bindman AB, Grumbach K, Vranizan K, et al. Selection and exclusion of primary care physicians by managed care organizations. The Journal of the American Medical Association. 1998; 279(9): 675-679. PMid: 9496985. http://dx.doi.org/10.1001/jama. 279.9 .675

[17] Murff HJ, Orav EJ, Lee TH, et al. Patient satisfaction profiling of individual physicians: Impact of panel status. Journal of Evaluation in Clinical Practice. 2004; 10(4): 553-561. PMid: 15482419. http://dx.doi.org/10.1111/j.1365-2753.2003.00482.x

[18] Forrest CB, Shi L, von Schrrader S, et al. Managed care, primary care, and the patient-practitioner relationship. Journal of General Internal Medicine. 2002; 17(4): 270-277. PMid: 11972723. http://dx.doi.org/10.1046/j.1525-1497.2002.10309.x

[19] Frankel RM, Levinson W. Back to the future: Can conversation analysis be used to judge physicians' malpractice history? Communication \& Medicine. 2014; 11(1): 27-39. http://dx.doi.org/10.1558 /cam.v11i1.20265

[20] Stelfox HT, Gandhi TK, Orav EJ, et al. The relation of patient satisfaction with complaints against physicians and malpractice lawsuits. The American Journal of Medicine. 2005; 118(10): 1126-1133. PMid: 16194644. http://dx.doi.org/10.1016/j.amjmed. 2005.01. 060

[21] Blackston WB, Bouldin MJ, Brown CA, et al. Malpractice risk prevention for primary care physicians. The American Journal of the Medical Sciences. 2002; 324(4): 212-219. PMid: 12385494 http://dx.doi.org/10.1097/00000441-200210000-00008

[22] Studdert DM, Mello MM, Gawande AA, et al. Claims, errors, and compensation payments in medical malpractice litigation. New England Journal of Medicine. 2006; 354(19): 2024-2033. PMid: 16687715. http://dx.doi.org/10.1056/NEJMsa054479

[23] Lieber EM. Medical malpractice reform, the supply of physicians, and adverse selection. Journal of Law and Economics. 2014; 57(2): 501-527. http://dx.doi.org/10.1086/675236

[24] Academy of Managed Care Pharmacy. Managed Care Terms. 2014. Available from: http://www.amcp.org/ManagedCareTerms/. accessed July 27, 2015. 